\title{
COVID-19-induced exacerbation of chronic inflammatory demyelinating polyneuropathy
}

\author{
Eveline Van Looy ${ }^{1,2} \cdot$ Len Veenker $^{1,2} \cdot$ Aurelia Steyaert $^{1,2} \cdot$ Jo Leenders $^{1} \cdot$ Goedele Malfroid $^{1} \cdot$ Harald De Cauwer $^{1,2}($ )
}

Received: 12 December 2020 / Revised: 17 January 2021 / Accepted: 18 January 2021 / Published online: 19 February 2021

(c) Springer-Verlag GmbH, DE part of Springer Nature 2021

\section{Dear Sirs,}

Human coronaviruses, such as SARS-CoV-2, are known to cause a variety of neurological symptoms [1]. GuillainBarrè Syndrome (GBS) has been described in patients with COVID-19 pneumonia [2]. Thus far, exacerbation of chronic inflammatory demyelinating polyneuropathy (CIDP) has only been described in one patient with COVID-19 [3].

In November 2020 a 53-year-old Caucasian female was admitted to the emergency department with complaints of paraesthesia and numbness periorally and in the four extremities. She had a remarkable medical history of two episodes of GBS, in 1999 and 2006, the latter with automated ventilator need. She recovered relatively well, but CIDP was diagnosed not long after. She had since been stable with IVIg every 6 weeks. She reported myalgia (in the lower limbs and masticatory muscles), gait disturbances, and dyspnea. She did not report dysgeusia, anosmia, diarrhea, nor fever. Clinical examination showed absence of the ankle tendon reflexes, as was already present previously. Laboratory examinations revealed negative RT-PCR for SARS-CoV-2 with nasopharyngeal swab. CSF analysis was normal (Table 1). SARS-CoV-2-serology was negative. Spirometry showed a restrictive pattern (FEV1 61\%, FVC $60 \%$, FEV1/FVC 101\%). After 3 days her other tendon reflexes became attenuated in the upper, and absent in the lower limbs. Repeat CSF analysis on day 4 showed albuminocytological dissociation; exacerbation of CIDP was

Eveline Van Looy

Eveline.VanLooy@ziekenhuisgeel.be

1 Department of Neurology, Geel General Hospital, Ziekenhuis Netwerk Kempen, Ziekenhuis Geel, JB Stessenstraat 2, 2440 Geel, Belgium

2 Faculty of Medicine and Health Sciences, University of Antwerp, Wilrijk, Antwerp, Belgium diagnosed upon which IVIg $0.4 \mathrm{mg} / \mathrm{kg}$ were administered for 5 days.

The same day she developed tachypnea, dyspnea, desaturation and hypertension. Chest CT scan suggested a viral pneumonia (Fig. 1). Repeat RT-PCR for SARS$\mathrm{CoV}-2$ with nasopharyngeal swab was negative. SO2 dropped despite extra oxygen administration and tachypnea $(\mathrm{SO} 2=86 \%$ with $151 \mathrm{O} 2)$. She had to be intubated and was admitted to the ICU. Broncho-alveolar lavage (BAL) demonstrated the presence of SARS-Cov-2 RNA, finally confirming COVID-19 pneumonia. LMWH, piperacillintazobactam, and dexamethason were administered. After 7 days, she could be extubated and was transferred to the neurology ward without any remaining respiratory distress. After 1 month of rehabilitation muscle strength in upper limbs was $4+/ 5$, in lower limbs $4-/ 5$, electro diagnostic parameters demonstrated decreased amplitude at compound muscle action potential and reduced velocity $30 \mathrm{~m} / \mathrm{s}$ in the right median nerve, and no response at motor and sensory nerve action potentials in the lower limbs, comparable to earlier studies.

We suggest that COVID-19 triggered fulminant exacerbation of CIDP. In Abu-Rumeileh's CSF was normal [3]. A second CSF analysis in our patient, however, did show albuminocytological dissociation, suggestive of CIDP relapse. There was a delay in diagnosing COVID19 because of the false-negative laboratory testing. Currently, most patients are tested for COVID-19 by means of a nasopharyngeal swab on which PCR is performed. It is reported in several cases that it is possible for nasopharyngeal swab PCR to be negative, while PCR testing on BAL sample is positive [4]. We speculate that respiratory muscular weakness and inability to cough, causes upper respiratory tract viral load to be much lower than lower tract viral load in patients with GBS/CIDP. In our patient, 
Table 1 Results of repeat lumbar puncture and serum

\begin{tabular}{|c|c|c|c|}
\hline & Reference range & Day 1 & Day 4 \\
\hline \multicolumn{4}{|l|}{ Lumbar puncture } \\
\hline White-cell count $(/ \mu \mathrm{L})$ & $0-5$ & 4 & 4 \\
\hline Red-cell count $(/ \mu \mathrm{L})$ & $<1000$ & 300 & 100 \\
\hline Protein $(\mathrm{mg} / \mathrm{dL})$ & $<45$ & 36.8 & 77.8 \\
\hline Glucose (mg/dL) & $40-70$ & 75 & 79 \\
\hline \multicolumn{4}{|l|}{ Lab results } \\
\hline Red-cell count $\left(\times 10^{\wedge} 9 / \mathrm{L}\right)$ & $3.8-5.2$ & 4.4 & 4.7 \\
\hline Hemoglobin (g/dL) & $11.8-16$ & 13.3 & 14.1 \\
\hline $\begin{array}{l}\text { White-cell count } \\
\left(\times 10^{\wedge} 9 / \mathrm{L}\right)\end{array}$ & $3.5-11$ & 7.9 & 11.6 \\
\hline Platelet count $\left(\times 10^{\wedge} 9 / \mathrm{L}\right)$ & $150-400$ & 249 & 259 \\
\hline CRP (mg/L) & $<5$ & 11.8 & 73.4 \\
\hline Creatinine (mg/dL) & $0.57-1.11$ & 0.9 & 0.71 \\
\hline Ferritin $(\mu \mathrm{g} / \mathrm{L})$ & 10-204 & 79 & 403 \\
\hline D dimers $(\mu \mathrm{g} / \mathrm{L})$ & $0-549$ & 536 & 1998 \\
\hline Arterial blood gas & & & $\begin{array}{l}\text { After intuba- } \\
\text { tion and } \\
\text { FIO2 100\% }\end{array}$ \\
\hline $\mathrm{pH}$ & $7.35-7.45$ & & 7.32 \\
\hline $\mathrm{pCO}_{2}(\mathrm{mmHg})$ & $32.0-45.0$ & & 42.6 \\
\hline $\mathrm{pO}_{2}(\mathrm{mmHg})$ & $83.0-108.0$ & & 141.6 \\
\hline $\mathrm{SO}_{2}(\%)$ & $94-98$ & & 98 \\
\hline Base excess (mmol/l) & -3.0 to 3.0 & & -4.7 \\
\hline
\end{tabular}

we consider respiratory failure was mainly due to CIDP relapse, although a restrictive pattern was demonstrated in COVID-19 survivors [5].

After this unexpected turn of events, all patients and staff were tested for SARS-CoV-2: everyone tested negative, suggesting the community-acquired nature of our patient's COVID-19. One can hypothesize that a negative nasopharyngeal swab might indicate that the patienteven if positive on BAL_-is less contagious and, therefore, poses less of a risk to other patients or medical personnel.

SARS-CoV-2 infection might be not only associated with the development of AIDP but could represent a precipitating factor for clinical exacerbations in patients with CIDP and other immune-mediated neuromuscular diseases, such as Myasthenia Gravis [3].

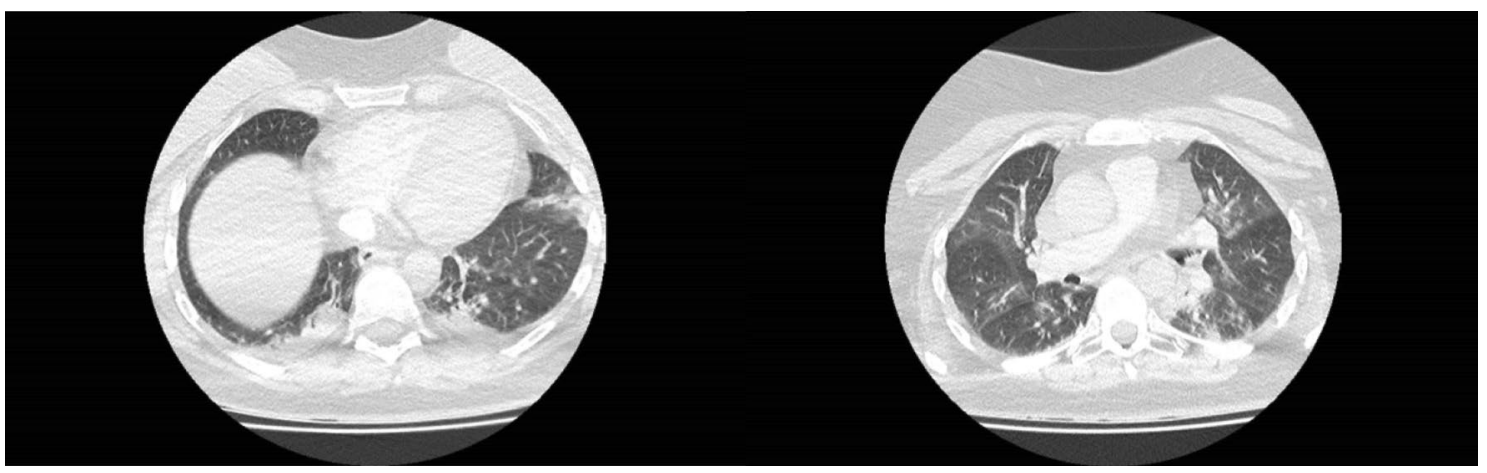

Fig. 1 Chest computed tomography scan showing bilateral atelectasis in the lower lungs with probable surinfection (left picture), diffuse ground glass opacities, mainly centrally in the upper and mid lungs, suggesting viral pneumonitis in lower, middle and upper lungs (left and right picture) 
Funding All authors report no financial disclosure.

\section{Compliance with ethical standards}

Conflicts of interest All the authors report no disclosure nor conflict of interest relevant to the manuscript.

Ethical approval This manuscript does not contain any studies with human participants or animals performed by any of the authors.

Informed consent Informed consent was obtained from all individual participants included in the study. Additional informed consent was obtained from all individual participants for whom identifying information is included in this article.

\section{References}

1. Verstrepen K, Baisier L, De Cauwer H (2020) Neurological manifestations of COVID-19, SARS and MERS. ActaNeurolBelg 120(5):1051-1060
2. Abu-Rumeileh S, Abdelhak A, Foschi M, Tumani H, Otto M (2020) Guillain-Barré syndrome spectrum associated with COVID-19: an up-to-date systematic review of 73 cases. J Neurol 25:1-38

3. Abu-Rumeileh S, Garibashvili T, Ruf W, Fangerau T, Kassubek J, Althaus K, Otto M, Senel M (2020) Exacerbation of chronic inflammatory demyelinating polyneuropathy in concomitance with COVID-19. J Neurol Sci 418:117106

4. Waked R, Makhoul J, Saliba G, Chehata N, Mortada S, Zoghbi A, Choucair J, Haddad E (2020) Are two consecutive negative RT-PCR results enough to rule out COVID-19? New Microbes New Infect 37:100750

5. Fumagalli A, Misuraca C, Bianchi A, Borsa N, Limonta S, Maggiolini S, Bonardi DR, Corsonello A, Di Rosa M, Soraci L, Lattanzio F, Colombo D (2020) Pulmonary function in patients surviving to COVID-19 pneumonia. Infection $28: 1-5$ 